\title{
Prácticas Artísticas Colectivas y sus Potenciales Socio-Políticos
}

\author{
Alix Didier Sarrouy ${ }^{1}$, Alina Cibea ${ }^{2}$ y Verónica Talellis ${ }^{3}$
}

\section{Claves de Lectura}

En este primer semestre del 2020, el contexto alarmista de la propagación del coronavirus COVID-19 pandémico revela algunas de las tensiones que rodean la idea de "colectivo". Por un lado, rompe las reuniones públicas y colectivas para evitar el contagio incontrolable del virus, trasladando el espacio público de la calle al mundo virtual. Por el otro, fortalece a los grupos profesionales y de voluntarios que necesitan unir sus esfuerzos para combatirlo, así como obliga al resto de las personas a detener su ritmo de vida habitual y a volver a estar juntas como familias en sus hogares. Al mismo tiempo que se están reforzando las fronteras territoriales, se evidencian las divisiones latentes entre un "nosotros" y "los otros", entre quienes son considerados parte de un colectivo imaginario y quienes no (Segato, 2007).

Los mundos de las artes, en los que hay obras singulares que resultan de contextos y colectivos cada vez más cercanos y articulados (Becker, 2010; Moulin, 1967; Small, 1977; Willis, 1990), están acostumbrados a las idas y vueltas entre la singularización, a veces como resultado de la discriminación e incomprensión, y la colectivización, debido a las múltiples influencias en el trabajo artístico y a su reutilización para fortalecer los colectivos, tanto privados como sociales. Atrás quedó la idea del artista aislado en las etapas de imaginación, creación y difusión de sus obras (Bürger, 1974). Efectivamente, el siglo XX fue particularmente fructífero en la escritura de más de cien manifiestos para importantes movimientos artísticos de todos los continentes (Lack, 2017). Además, tener una conciencia colectiva y auto-percibirse como colectivo lleva a

1 Centro Interdisciplinar de Ciências Sociais (CICS.NOVA), Faculdad de Ciências Sociais e Humanas, Universidade Nova de Lisboa, Portugal. Integrante del proyecto ArtCitizenship, financiado por Fundação para a Ciência e a Tecnologia (PTDC/SOC-SOC/28655/2017). Dirección electrónica: alixsarrouy@fcsh.unl.pt 2 Facultad Latinoamericana de Ciencias Sociales - sede Argentina y Universidad Nacional de Avellaneda. Integrante del Grupo de Investigación sobre Música e Inclusión. Dirección electrónica: acibea@gmail.com 3 Universidad de Buenos Aires - Facultad de Filosofía y Letras y Universidad Nacional de Avellaneda. Integrante del Grupo de Investigación sobre Música e Inclusión. Dirección electrónica: verohope@yahoo.com 
repercusiones en la sociedad. El colectivo es una de las fuerzas más deseadas en la política, pero también tiene el potencial de volverse muy temida (Cefaï 2007).

$\mathrm{Lxs}^{4}$ artistas por excelencia accionan y reaccionan creativamente a su entorno. Como veremos en este dossier temático, el ethos social que lxs influye puede adoptar una gran variedad de formas. Puede ser de naturaleza política, relacionado con cuestiones de identidad y pertenencia, inspirado en expresiones artísticas marginadas o en disputas sobre accesos desiguales a bienes materiales y simbólicos, entre muchas otras posibles influencias. Incluso la imagen del virus arriba mencionado tiene en sí un carácter estético, explotado por dibujantes y artistas digitales en GIF y memes, por ejemplo. ${ }^{5}$ Todo se vuelve más complejo cuando la distancia entre lo local y lo global se acorta.

La innegable influencia de los procesos de globalización ha permitido que una creciente y diferenciada cantidad de ciudadanxs puedan tener un relativo acceso y apropiación de espacios públicos de diversa índole, sumado al uso de nuevas tecnologías en comunicación e información. Con múltiples reverberaciones a distintos niveles de la sociedad, las motivaciones y demandas de sus miembros se fortalecen, al igual que los métodos de luchas contestatarias y de resistencia (Campbell y Martin, 2006; Carmo, 2019; Vélez-Vélez y Villarrubia-Mendoza, 2019). El libre acceso a múltiples recursos ha animado, diversificado y radicalizado los conflictos culturales, entendidos como disputas por los sentidos en una sociedad. Es el seno de estas controversias donde nacen también ciertas prácticas artísticas como posibles acciones y respuestas frente a las demandas sociales, políticas y culturales, generando a su vez nuevas demandas en un ciclo que se retroalimenta (Infantino, 2019b; Mercado, 2018).

Por un lado, encontramos que en el campo social las propuestas de acción colectiva que buscan de alguna manera intervenir desde, para o con el arte varían según el país y las localidades donde se están desarrollando. Como plantea el artista e investigador colombiano Fernando Escobar Neira, las intervenciones artísticas "difieren en las tácticas que emplean para insertarse y articularse a circuitos no artísticos; en las estrategias implementadas para vincularse efectivamente con la institucionalidad del campo del arte local y al mismo tiempo, resistir y desviar la corrección política que le es propia; en las representaciones de lo artístico de las que se sirven para intervenir para apropiar recursos; y en el ideario que movilizan en términos políticos, sociales y artísticos." (Escobar Neira, 2012: 23)

Por otro lado, son los intersticios y las tensiones sociales, económicas, políticas y culturales los contextos en los cuales se encuentran insertxs lxs artistas, públicos, gestorxs y demás productorxs culturales. En estos contextos, artistas de distintas disciplinas han ido creando múltiples formas de organizarse para reactivar la capacidad cultural instalada en sus territorios (Palacios Garrido, 2009; Echeverría, 2019; Moyano, 2019). Las formas de intervención que estos grupos generan están, entre otras, evidenciando las posibilidades de transformación que se pueden realizar desde sus propias prácticas artísticas (Infantino, 2019a; Diz, 2019; Greco, 2019; Berzel, 2019).

4 Hemos optado por marcar la diversidad de género usando la "x" en esta Introducción. Sin embargo, en los artículos se han respetado las formas elegidas por lxs autorxs, por eso no existe un criterio unificado de referencia en el conjunto del dossier.

5 Ver por ejemplo: https://www.sapeople.com/2020/03/06/coronavirus-jokes-and-memes/ (visitado el 16.03.2020); https://www.ibahia.com/brasil/detalhe/noticia/internet-explode-em-memes-em-razao-da-pandemia-do-coronavirus-veja/ (visitado el 16.03.2020). 


\section{CO-EDICIÓN DEL DOSSIER TEMÁTICO}

La colaboración como co-editorxs del presente dossier es en simultáneo resultado y punto de partida de una vinculación académica cuyos objetivos son profundizar, complejizar y fomentar el diálogo entre múltiples perspectivas epistemológicas, discursivas y académicas provenientes de distintas geografías. Las motivaciones que impulsaron la elección de esta temática se conectan directamente con nuestras propias investigaciones, las cuales a menudo nos interpelan no sólo como individuos, sino también como parte de los colectivos que integramos.

Provenientes de distintas disciplinas de las ciencias sociales - ciencias políticas, antropología y sociología - y oriundos de diferentes países, lxs tres compartimos el disfrute de las artes, inmersxs tanto en el terreno del hacer (música y danza), como en el de la investigación. Alina Cibea, rumana radicada en Argentina y Austria, es politóloga con trayectoria en investigación aplicada en el desarrollo de políticas públicas en las áreas de migración, integración y anti-discriminación (Reichel y Cibea, 2013; Kraler, Reichel y Cibea, 2013; Cibea et al., 2019). Verónica Talellis, antropóloga argentina, estudia temáticas relacionadas con la música como expresión artística para la inclusión y la transformación social y se desempeña como gestora cultural en el ámbito de las políticas públicas de la Ciudad de Buenos Aires (Talellis, 2019). Junto con la antropóloga Karen Avenburg, las tres co-fundaron el Grupo de Investigación sobre Música e Inclusión, radicado en la Universidad Nacional de Avellaneda, en la Provincia de Buenos Aires. El grupo está conformado por investigadorxs y estudiantxs cuyas temáticas de investigación problematizan las prácticas musicales que buscan la inclusión, integración y/o transformación social (Avenburg, Cibea y Talellis, 2017). Por su parte, Alix Sarrouy, músico, performer y sociólogo francés actualmente residiendo en Portugal, viene trabajando desde hace más de diez años en torno a las cuestiones del uso de las artes como herramienta de educación e inclusión en contextos socioeconómicos desfavorecidos, utilizando las ciencias sociales para comprender mejor las acciones de animación y de mediación sociocultural en Europa y América Latina (Sarrouy, 2016, 2017, 2018). Es miembro del proyecto de investigación ArtCitizenship, que organiza la conferencia anual COMbART en Portugal.

En 2017, nos hemos encontrado en el marco de un intercambio entre la Universidad de Avellaneda y el Laboratorio de Cambio Social y Político de la Universidad Paris-Diderot. Pudimos compartir relatos de campo, observaciones y reflexiones sobre nuestras experiencias de investigación y los marcos epistemológicos empleados en distintos países de Europa y Latinoamérica. De esa experiencia, y con ánimo de continuar el diálogo académico, seguimos la colaboración. En 2019 el grupo argentino publicó el libro Las artes frente a la exclusión. Manifestaciones artísticas como prácticas de inclusión, integración y transformación social que reúne trabajos sobre distintas experiencias latinoamericanas y europeas (Avenburg, Cibea y Talellis, 2019), donde Alix Sarrouy contribuyó con un artículo.

En ese mismo año, Peter Anton Zoettl y Ricardo Campos, editores de la revista Cadernos de Arte y Antropología, nos invitaron para co-editar un dossier temático en torno a un tema que reflejase las cuestiones de relevancia actual en nuestros campos de investigación y los cuales se beneficiarían de un diálogo trans-continental e inter-disciplinario. Partiendo de nuestros intereses académicos compartidos sobre las dimensiones políticas y sociales de las intervenciones artísticas, fue fácil identificar el enfoque que le queríamos dar a esta convocatoria. Por un lado, apuntamos a reunir investigaciones que analicen y problematicen en clave de lo "colectivo" las tensiones y disputas en torno a las prácticas artísticas. Por el otro lado, a partir del análisis de 
estas prácticas buscamos visibilizar investigaciones que rompan con las epistemologías hegemónicas y que utilicen formas alternativas de comunicar saberes. Para ello no solo convocamos artículos con formato académico, sino que también contribuciones que indaguen las prácticas colectivas desde otros soportes (ensayo fotográfico, diario de campo, documental multimedia etc.).

\section{ORGANIZACIÓN DE LOS ARTíCULOS}

La selección de los textos aquí propuestos corresponde a los principios de apertura y confluencia que figuraron en la convocatoria del dossier. Los artículos están escritos en cuatro idiomas (Portugués, Español, Francés e Inglés), por seis autorxs que provienen de distintas regiones (Argentina, Canadá, Portugal, Francia) y analizan prácticas que se desarrollan en Argentina, Brasil, Bolivia y Portugal. Esta multiplicidad no es casual; a través de ella quisimos poner de manifiesto los diferentes lugares de escucha y habla (Chakrabarty, 2008; Ribeiro, 2017). Estos lugares, reflejados en la observación y en la escritura etnográfica, también están fuertemente influenciados por el hecho de que varixs de lxs autorxs aquí publicadxs son al mismo tiempo científicxs sociales y artistas practicantes.

Además, los contextos sociales en cuales se desarrollan las prácticas que ellxs están analizando son espacios marcados por disputas políticas muy visibles, frente a las cuales sus propios escritos y prácticas artísticas representan formas concretas de intervención social y actos de posicionamiento político. Es por ejemplo el caso de Brasil bolsonarista (Cézard), de la Argentina kirchnerista (Spinetta) y de las luchas indigenistas de una Bolivia con sus propias crisis políticas (Ansari). Por lo tanto, son escritos del tiempo presente, que revelan las motivaciones y complejidades de las creaciones artísticas contemporáneas, donde están puestas en juego ciertas nociones de "lo colectivo" y se revelan las relaciones y tensiones que existen con "lo individual". Es en torno a estos ejes principales que se realizó la organización de los artículos, en dos binomios y otros dos artículos separados.

El artículo que abre el presente dossier está a cargo de la investigadora Julieta Infantino y presenta un panorama amplificado y complejo que permitirá poner en diálogo algunas conceptualizaciones claves para pensar la problemática del presente dossier. Las tensiones que la autora señala en el campo del arte y de la política se constituyen en herramientas que habilitan la reflexión sobre el potencial socio-político de las prácticas colectivas y sus posibles alcances. Si bien es lícito aclarar que su trabajo se centra puntualmente en Argentina, consideramos que sus aportes iluminan debates y fenómenos que se dan también en otras regiones geográficas, atravesando problemáticas que encontramos tanto a nivel local como global.

En Sentidos de la potencialidad critica, politica, transformadora del arte, Infantino propone problematizar desde una mirada crítica cómo en las últimas décadas artistas, trabajadorxs culturales, educadorxs, diseñadorxs de políticas públicas e intelectuales, entre otrxs, vienen desplegando una variedad de propuestas que promueven la transformación social desde los más diversos lenguajes artísticos. Los mismos conjugan, colectivizan, territorializan acciones concretas de intervención en las situaciones de desigualdad social latinoamericana, disputando una resignificación del rol del arte en tanto herramienta de intervención social y disputa política por la ampliación de derechos. Este trabajo propone una sistematización de algunas líneas 
de reflexión en relación a los usos sociales y políticos del arte para recorrer procesos históricos, tensiones y disputas que evidencian cómo los sentidos con los que se connota el potencial transformador, crítico/político del arte no son unívocos y emergen de coyunturas diferenciales, así como de intereses y contextos político-ideológicos específicos.

A continuación, el primer binomio de artículos está agrupado en torno al posicionamiento de lxs investigadorxs como artistas y militantes/activistas que apuntan a visibilizar problemáticas sociales locales y globales desde un lugar de práctica encarnada. A través de la propia participación en las expresiones artísticas que luego analizan, se pone de manifiesto la permeabilidad de lxs observadorxs, sus crecientes involucramientos personales y profesionales con el arte comprometido. También encontramos reforzado el compromiso de usar la acción artística y de intervención en el espacio público desde un lugar de reflexión crítica, que a posteriori está nuevamente analizado y transmitido a través de divulgaciones de índole académica. Asimismo, ambos artículos de este primer binomio miran cómo la intersección entre las esferas política y personal puede formar la base del activismo político, aquí manifestado a través de prácticas artísticas que implican distintas formas de grupalidad. Además, este tipo de participación como práctica encarnada de intervención e investigación nace y se vuelve valiosa como forma de contestación y resistencia en contextos altamente politizados, como acción y reacción desde las prácticas artísticas colectivas frente a las tensiones políticas, sociales y económicas vividas en sociedad. Desde un punto de vista epistemológico, el tipo de posicionamiento aquí propuesto interpela el involucramiento distante tradicionalmente considerado como correspondiendo a las miradas "objetivas" de lxs investigadorxs, supuestamente neutrxs, equidistantes y que hasta recién automáticamente denominadxs por el genérico género masculino. Si bien las dos investigadoras cuyos artículos están presentados en esta sección se auto-posicionan lejos de estas suposiciones, eso no obstaculiza la riqueza del análisis y los argumentos allí propuestos.

En su artículo Are Female Clowns Politically Incorrect? Case Study on Female Clowns' Political Engagement at the 7th Esse Monte de Mulher Palhaça Festival in Rio de Janeiro, la investigadora y clown Delphine Cézard analiza las dimensiones políticas de un festival de clown bianual que se desarrolla en Rio de Janeiro y está dedicado específicamente al clown femenino (clownes). Examinando las performances, así como la mera presencia de estos actos en los espacios públicos y la existencia de una comunidad de clowns femeninos de Brasil y Latinoamérica, la autora se pregunta por las motivaciones y los sentidos que toman las acciones de las clownes en cuanto formas de participación en la arena política y en la sociedad.

Por su lado, la investigadora Valeria Spinetta propone en su artículo Arte y política: las intervenciones públicas del Frente Cultural "Maria Remedios del Valle" (Avellaneda, 2018-2019) un análisis de la acción colectiva y militante que asume un colectivo de artistas militantes de la ciudad de Avellaneda, en el conurbano bonaerense de Argentina. El trabajo focaliza en las reivindicaciones y en las intervenciones artístico-culturales, entendidas en términos de performance, que el Frente Cultural "María Remedios del Valle" realizó en el espacio público y virtual, entre junio de 2018 y julio de 2019.

El segundo binomio de artículos para este dossier junta trabajos que tienen en común el carácter a priori marginal de las plataformas escogidas como medio de comunicación: los blogs de poesía y las banderas confeccionadas por lxs fans de un músico popular. En ambos casos lo colectivo es esencial, tanto para la creación como para la expresión de los sentimientos. Otro punto común es el amateurismo de lxs actores involucrados, no en el sentido habitualmente 
peyorativo, sino en el sentido utilizado por Antoine Hennion - el aficionado como siendo aquel que "ama" su forma de expresión artística (2004, 2009). A la legitimidad centenaria del mundo de la poesía agregamos la creación de banderas para ser desfiladas en conciertos, forma de expresión estereotipadamente vista como un camino menor y asociada con una cultura escrita con "c" (minúscula). Nos interesa esta sobreposición tensa, que particularmente se revela en los puntos comunes de aquello que Bernard Lahire denominaba "disonancias culturales" (Lahire, 2004), es decir las posibilidades de que a una persona le gusten lxs poetas de referencia al mismo tiempo que pueda disfrutar de un concierto de música popular con una bandera en su mano.

A través del artículo de la socióloga portuguesa Rita Grácio Uma gaveta mais pública: a blogosfera como espaço colectivo de prácticas socio-poéticas, se analizan los aspectos colectivos del mundo contemporáneo de la poesía, específicamente en el caso de lxs poetas-bloggers en Portugal. El mundo digital termina siendo un promotor de intercambios simbólicos y físicos, siempre entre las tensiones individual-colectivo, lectura-escritura, local-global. Pero la autora resalta que los blogs también se pueden volver escenarios de jerarquías donde lxs poetas aficionadxs buscan ser legitimadxs por sus pares. Son medios de activismo en los cuales se toman decisiones contra-hegemónicas, tanto frente a una cierta estética poética canónica, como frente a una superioridad reservada al libro como escenario supremo de acreditación de lxs autorxs.

De Argentina, Nicolas Aliano analiza en su artículo De aficiones, rituales y mundos de arte: un análisis de un proceso de creación colectiva popular una dimensión específica de una de las prácticas de afición de lxs seguidores de un cantante de rock popular argentino, Carlos "Indio" Solari. La producción colectiva de banderas por una parte del público y sus familias genera no solo nuevas expresiones artísticas sino también nuevas redes colaborativas, visibilizando un "mundo de arte" popular (Becker, 2008; Willis, 2014) en torno a la música. La investigación propone un análisis de los procesos de creación colectiva, al tiempo que indaga sobre el potencial social y político de esta práctica, específicamente sobre la relación que se establece entre lo individual y lo colectivo. El autor argumenta que entre estos dos polos se configura un mundo de prácticas sustentado por lxs fans. Lxs mismxs se comprometen y elaboran sentidos de pertenencia a partir del acto de compartir una afición en donde, a la vez que "hacen arte", procesan colectivamente diversas pruebas existenciales.

Para cerrar el presente dossier temático hemos elegido un texto que, en términos de formato, propone un abordaje diferente de escritura cualitativa. El artículo de Jordie Ansari Balade dans les ruelles paceñas sur les traces de l'art mural urbain representa un verdadero viaje guiado por el arte mural de las calles de La Paz, Bolivia. Alejándose del formato tradicional de un artículo científico, éste es un relato etnográfico sobre las historias contadas en grandes murales urbanos, en los cuales se refleja un contexto social denso, complejo y sangriento, aunque de cierta forma esperanzador. El artículo deja en claro que el arte mural en Bolivia está vivo y que, a veces mezclado con las técnicas contemporáneas del graffiti, reviste las paredes del pueblo para reflejar una realidad social colectiva y para expresar desafíos emergentes. 


\section{CONSIDERACIONES FINALES Y AGRADECIMIENTOS}

Para concluir, esperamos que este dossier pueda facilitar la mejor comprensión de las distintas potencialidades que tienen las prácticas artísticas colectivas y sus implicancias en nuestras sociedades, particularmente para los debates en torno a la transformación social. Es nuestro deseo que las cuestiones aquí tratadas despierten el interés de otrxs investigadorxs, artistas, militantes y activistas, y que aporten herramientas concretas para pensar y accionar.

Los artículos aquí reunidos muestran lo que las prácticas artísticas que implican la colaboración de varias personas y que se realizan desde premisas de autodeterminación pueden aportar a los debates sobre modelos alternativos de organización social en nuestras sociedades. Frente a las opciones provenientes de las dos corrientes dominantes en la actualidad, el neoliberalismo y el reaccionarismo conservador, el análisis de las dinámicas de interacción social que se dan en torno al ejercicio colectivo de expresiones creativas a menudo marginalizadas presenta alternativas concretas basadas en prácticas de cooperación, solidaridad y reciprocidad.

Por lo último, queremos reiterar que la riqueza de la presente colección de artículos proviene indudablemente de la amplia diversidad de voces que están representadas en la variedad de abordajes epistemológicos, de registros de lenguajes académicos y no académicos empleados, de las expresiones artísticas analizadas, así como de los espacios geográficos de procedencia de estas experiencias y de los idiomas en cuales se eligió transmitir el conocimiento. Toda esta multiplicidad no es casual, sino que es el resultado de una búsqueda intencional del equipo editorial, que en sí mismo es un ejemplo de colectivo multidisciplinario, transcultural, trans-epistemológico y pluri-género.

Nuestros agradecimientos van en primer lugar a Peter Anton Zoettl y a Ricardo Campos, editores generales de la Revista Cuadernos de Arte y Antropología, por darnos la posibilidad de abrir un espacio de debate e intercambio que permitió explorar los temas abordados en este dossier. A lxs evaluadorxs, por su profesionalismo y sus profundas revisiones. Queremos resaltar que, para asegurar un equilibrio, cada artículo fue revisado por dos evaluadorxs, unx proveniente de Europa, otrx de Latinoamérica. A lxs 26 autorxs que respondieron a la convocatoria con muy valiosos aportes, lamentando no haber podido incluir a todxs, dadas las limitaciones de espacio y las normas editoriales. A lxs 6 autorxs cuyas contribuciones fueron aceptadas, por su intenso trabajo, seriedad y compromiso demostrados a lo largo de los intercambios realizados durante el proceso.

Finalmente, esperamos que lxs lectorxs, más allá de encontrarse con material valioso y relevante para sus propios trabajos e investigaciones, también disfruten de la lectura de todo este abanico de perspectivas. Es nuestro deseo continuar el diálogo aquí empezado y ampliarlo cada vez a más voces.

\section{BiBLIOGRAFíA}

Avenburg, K., Cibea, A. y Talellis, V. (2017). Las orquestas infantiles y juveniles del Gran Buenos Aires. Estudio descriptivo del panorama de proyectos y programas vigentes entre 2014 y 2015. Foro de educación musical, artes y pedagogias, Vol. 2. Num. 2, pp. 13-57. 
Avenburg, K., Cibea, A. y Talellis, V., comps. (2019). Las artes frente a la exclusión. Manifestaciones artísticas como prácticas de inclusión, integración y/o transformación social. Buenos Aires: UNDAV Ediciones.

Becker, H. (2010). Les mondes de l'art. Paris: Flammarion.

Becker, H. (2008). Los mundos del arte. Bernal: Universidad Nacional de Quilmes.

Berzel, M. (2019). Experiencias de arte y transformación social con jóvenes: procesos de apropiación desde la perspectiva de los/as participantes del Circo del Sur. Disputar la cultura. Arte y Transformación Social, Julieta Infantino (ed.), pp. 201-238. Buenos Aires: RGC ediciones.

Bürger, P. (2000) [1974]: Teoría de la vanguardia, Península, Barcelona.

Campbell, M. S. y Martin, R. (2006). Artistic Citizenship A Public Voice for the Arts. New York: Routledge.

Carmo, A. (2019). O Teatro do Oprimido na periferia de Lisboa. Cidade, cidadania e arte. Lisboa: Outro Modo, Le Monde diplomatique.

Chakrabarty, D. (2008): Al margen de Europa. Pensamiento poscolonial y diferencia histórica. Barcelona: Tusquets Editores.

Cibea, A., Avenburg, K., Talellis, V. y Juarez, C. (2019). Introducción. Las artes frente a la exclusión. Manifestaciones artísticas como prácticas de inclusión, integración y/o transformación social, Avenburg, K., Cibea, A. y Talellis, V., (comps.), pp. 11-33. Buenos Aires: UNDAV Ediciones.

Cefaï, D. (2007). Pourquoi se mobilise-t-on? Les théories de l'action collective. Paris: La Découverte.

Diz, M. L. (2019). Teatro x la Identidad: la herramienta emblemática de la producción cultural de Abuelas de Plaza de Mayo. Las artes frente a la exclusión. Manifestaciones artísticas como prácticas de inclusión, integración y/o transformación social, Avenburg, K., Cibea, A. y Talellis, V., (comps.), pp. 209-223. Buenos Aires: UNDAV Ediciones.

Echeverría, A. (2019). Prácticas de creación artística en la intervención política. El Congreso Escena Política. Disputar la cultura. Arte y Transformación Social, Julieta Infantino (ed.), pp. 239-272. Buenos Aires: RGC ediciones.

Escobar Neira, F. (2012). Culturas del Espacio y Procesos artísticos colectivos-participativos. Casos recientes en México, Bogotá y Medellín. Revista PraxisESaber. Vol. 3, Num. 6, Segundo Semestre, pp. 17-42.

Greco, L. R. (2019) 'Es del pueblo, es nuestra”. Transformación social y capoeira de calle en el sur de Brasil. Las artes frente a la exclusión. Manifestaciones artísticas como prácticas de inclusión, integración y/o transformación social, Avenburg, K., Cibea, A. y Talellis, V., (comps.), pp. 252-273. Buenos Aires: UNDAV Ediciones.

Hennion, A. (2004). Une sociologie des attachements. D'une sociologie de la culture à une pragmatique de l'amateur. Societes, 2004(85 3), pp. 9-24. Disponible: https://doi.org/10.3917/ soc.085.0009.

Hennion, A. (2009). Réflexivités. L'activité de l'amateur. Réseaux, 153(1), 55-78. Disponible: https://doi.org/10.3917/res.153.0055.

Infantino, J., ed. (2019a). Disputar la cultura. Arte y Transformación Social. Buenos Aires: RGC ediciones.

Infantino, J. (2019b). Transformar, resistir, demandar. Disputas político-culturales hacia una ley nacional de circo. Disputar la cultura. Arte y Transformación Social, Julieta Infantino (ed.), pp. 273-310. Buenos Aires: RGC ediciones.

Kraler, A., Reichel, D. y Cibea, A. (2013) Evaluation of the Immigrant Citizens Survey (ICS). Vienna: ICMPD. 
Lack, J. (2017). Why are we "artists"? 100 World Art Manifestos. UK: Penguin Random House UK.

Lahire, B. (2004). La Culture des individus. Dissonances culturelles et distinction de soi. Paris: La Découverte.

Mercado, C. (2018). Trayectorias de Teatro Comunitario en Buenos Aires. Politicas culturales, autogestión y sentidos del arte en disputa. (Tesis de doctorado en Antropología Social). Buenos Aires: Universidad de Buenos Aires.

Moulin, R. (1967). Le Marché de la peinture en France. Paris: Minuit.

Moyano, M. (2019). Creación, gestión e institucionalización de una organización socio-artística: el caso de ph15. Disputar la cultura. Arte y Transformación Social, Julieta Infantino (ed.), pp. 133-167. Buenos Aires: RGC ediciones.

Palacios Garrido, A. (2009). El are comunitario: origen y evolución de las prácticas artísticas colaborativas. Arteterapia - Papeles de arteterapia y educación artística para la inclusión social, 197 (49), pp. 197-211.

Reichel, D. y Cibea, A. (2013). The Use of Indicators for Measuring the Impact of Integration Policy in Europe [Die Verwendung von Integrationsindikatoren zur Messung der Wirkung von Integrationspolitik in Europa]. Migration und Integration. Wissenschaftliche Perspektiven aus Österreich, Jahrbuch 2/2013. Vienna: Vienna University Press.

Ribeiro, D. (2017). O que é lugar de fala? Belo Horizonte: Letramento.

Sarrouy, A.D. (2016). Atores da educação musical: etnografia comparativa entre três núcleos que se inspiram no programa El Sistema na Venezuela, no Brasil e em Portugal. Universidade do Minho. Disponible: http://repositorium.sdum.uminho.pt/handle/1822/48595.

Sarrouy, A.D. (2017). Adapter pour mieux adopter - Ethnographie dans des núcleos d'éducation musicale au Venezuela et au Portugal. Sociologia OnLine, (15), pp. 15-30. ISSN: 1647-3337

Sarrouy, A.D. (2018). Madres del núcleo Santa Rosa de Agua. Revista Estudios Culturales Comparativos de El GOVDIV, (5).

Segato, R. (2007). La nación y sus otros: raza, etnicidad y diversidad religiosa en tiempos de políticas de la identidad, Buenos Aires: Prometeo.

Small, C. (1977). Music, society, education. London: John Calder.

Talellis, V. (2019). Políticas(s) y cultura. Reflexiones en torno a la implementación de una propuesta pública estatal de orquesta juvenil en la Ciudad de Buenos Aires. Disputar la cultura. Arte y Transformación Social, Julieta Infantino (ed.). Buenos Aires: RGC ediciones.

Vélez-Vélez, R., y Villarrubia-Mendoza, J. (2019). Interpreting mobilization dynamics through art: A look at the DREAMers Movement. Current Sociology, 67(1), 100-121. Disponible: https://doi.org/10.1177/0011392118807517.

Willis, P. (1990). Common Culture: Symbolic Work at Play in the Everyday Cultures of the Young. London: Open University Press.

Willis, P. (2014). Profane Culture (Updated Ed). Princeton University Press. 